\title{
mTOR and post-translational modifications rely on mitochondrion as the arsenal for cellular metabolism regulation
}

\author{
ZHUGE ChunChun $\mathrm{J}^{1}$, CHEN Si $\mathrm{J}^{2}$ \& CHIN Y Eugene $\mathrm{e}^{1,2^{*}}$ \\ ${ }^{1}$ Shanghai Chest Hospital, Shanghai Jiaotong University, Shanghai 200031, China; \\ ${ }^{2}$ Institute of Health Sciences, Chinese Academy of Sciences; School of Medicine, Shanghai Jiaotong University, Shanghai 200031, China
}

Received April 26, 2015; accepted June 6, 2015; published online July 23, 2015

Citation: Zhuge CCJ, Chen SJ, Chin YE. mTOR and post-translational modifications rely on mitochondrion as the arsenal for cellular metabolism regulation. Sci China Life Sci, 2015, 58: 810-812, doi: 10.1007/s11427-015-4909-1

Mitochondrion is considered as the "powerhouse of the cell" almost immediately since its discovery. It carries less than 1,000 proteins and some nucleotides as well as lipids. Mitochondrion is also discovered as the "lung of the cell" for its role in cellular respiration. As the important cellular organelle, there are many metabolic processes occurred in mitochondria.

The mammalian target of repamycin (mTOR), or FKBP12-rapamycin associated protein 1 (FRAP1), is a highly conserved protein kinase which contains 2,549 amino acids. More and more evidence show that mTOR can shuttle to mitochondria and play some role in cell metabolism. Just as mentioned above, mTOR can regulate different metabolic products synthesis with post-translational modification, mainly phosphorylation of mTOR itself and its down-stream protein [1].

Metabolism is found greatly conducted by mTOR signaling pathway since mTOR was identified in 1990s. It can influence protein synthesis, lipid biogenesis and energy regulation. The metabolites provide signals of cellular nutrient state and trigger different response on mTOR pathway. Accompany with other components, mTOR construct two different protein complexes, mTORC1 (mTOR complex 1) and mTORC2. The mTORC1 is composed of mTOR, Raptor, G $\beta$ L mLST8, (mammalian lethal with SEC13 protein 8), Deptor and PRAS40 (a $40 \mathrm{kD}$ Pro-rich Akt substrate). mTORC2 consists of mTOR, Raptor, G $\beta \mathrm{L}$

*Corresponding author (email: yechin@ sibs.ac.cn)
(mLST8), RICTOR (rapamycin-insensitive companion of mTOR), mSIN1 (SAPK-interacting protein 1), PRR5 (proline rich protein 5) and PRR5L (proline rich protein 5-like), which were also known as Protor1 and Protor2 [2]. Both of the two mTOR complex play critical role in biological process.

Protein post-translational modification is an important method to control or regulate the protein function after its synthesis. Protein function is regulated by adding different organic groups, such as methyl group, acetyl group, phosphate group and ubiquitin, on the side chain of amino acid of the protein. These modifications could change the surface charge or the 3D structure of the protein which could interfere the protein-protein interaction. In cells, these modifications are usually through enzymatic reaction. In mTOR case, the protein itself can be phosphorylated at multiple sites. And also, mTOR can regulate its substrates and downstream molecules by post translation modification such as phosphorylation, acetylation and ubiquitination $[3,4]$. With these modification, mTOR can manipulate several biochemistry process happened in mitochondria and critical for cell metabolism.

ATP (adenosine triphosphate) synthesis is the most important mitochondrial function which would supply the energy that the cell need. As an energy sensor, mTOR is directly regulated by cellular ATP concentration, which triggers AMPK (AMP-activated protein kinase)/mTOR pathway to regulate the intracellular ATP level. In this regulation, phosphorylation plays a critical role. During fasting, 
the ratio of ATP:ADP drops, AMPK is activated and induces TSC2 (tuberous sclerosis 2) phosphorylation, which increases the GAP (GTPase-activating protein) activity of TSC2 towards Rheb and reduces mTORC1 activation [5]. In other way, AMPK can inhibit mTORC1 activity by phosphorylated Raptor, the subunit of mTORC1, when there is an energy shortage [6]. The mTORC1 can also increase oxidative respiration by phosphorylating STAT3 (signal transducer and activator of transcription 3). Recently, there are direct evidences show that $\mathrm{mTORC} 1$ regulates ATP production in mitochondria through 4E-BP phosphorylation [7]. Besides that, mTOR can regulate insulin sensitivity, which controls the glucose level in the cells, by phosphorylation and downstream phosphorylation. In mice, overexpression of hNAG-1 (human non-steroidal antiinflammatory drug-activated gene-1) would reduce mTOR phosphorylation at serin2884, which leads the improvement of insulin sensitivity [8]. In another hand, glucose uptake is inhibited by knock-down of a small peptide Nesfatin-1, and this peptide would also increase mTOR S2884 phosphorylation and induce STAT3 phosphorylation at Y705 and S727 [9]. With all these findings, we can conclude that phosphorylation of mTOR and its downstream molecules can regulate oxidative respiration in mitochondria and ATP generation.

Acetyl-CoA is produced in mitochondria during the TCA cycle and oxidation of pyruvate. As an important metabolite, Acetyl-CoA conveys the carbon atoms within the acetyl group to the citric acid cycle (Krebs cycle) to be oxidized for energy production. Acetyl-CoA is catalyzed into malonyl-CoA by acetyl-CoA carboxylase (ACC), at which point malonyl-CoA is destined to feed into the fatty acid synthesis pathway [10].

The mTOR can regulate the activity of some vital enzymes in acetyl-CoA synthesis along with lipid generation. Though mTOR has no effect on the Acetyl-CoA synthetic process in mitochondria, it can regulate the downstream reaction in which acetyl-CoA would take part. mTOR activity could increase the synthetic rates of ACC $\alpha$ and fatty acid synthase (FSN) [11]. The mTORC1 could activate SREBP-1 (sterol regulatory element-binding protein 1) by S6K1 dependent and independent manner [12]. In S6K1 independent SREBP-1 regulation of Acetyl-CoA synthesis, Lipin-1 was phosphorylated and inhibited. LIPIN1 is a phosphatidic acid phosphatase which could inhibit SREBP-1. The mTORC1 can directly phosphorylate LIPIN1 and inhibit its activity [13]. Thus mTORC1 can affect the Acetyl-CoA synthesis indirectly through Lipin-1 phosphorylation.

As was shown, in de novo lipogenesis, Acetyl-CoA's concentration is regulated by $\mathrm{PI} 3 \mathrm{~K} / \mathrm{Akt} / \mathrm{mTOR}$ pathway, and this regulation is strongly driven by insulin [14]. Insulin could induced Akt phosphorylation through insulin receptor. The activated Akt would induce the expression of genes which are involved in lipogenesis [15]. There are re- ports showed that SREBP-1, which was mentioned above, could also regulated by Akt and play some role in lipogenesis [16,17].

We could draw the conclusion that $\mathrm{mTOR}$ could regulate ATP and Acetyl-CoA synthesis in mitochondria with post translational regulation, usually phosphorylation. There were some evidence shown mTOR could regulate cell metabolism by acetylation-deacetylation process on downstream molecules, though there are no published report which support this. By control the ATP and Acetyl-CoA synthesis, mTOR would dominant the cellular energy resource and regulate multiple enzyme catalysis which was extremely important for cell metabolism. So, we could regard mTOR in mitochondria as an arsenal of cell metabolism. Through mTOR, many components (free molecular) can assemble into different weapons (biomacromolecules) and these weapons can help the cells to defense themselves and transfer their genetic information.

1 Tao Z, Barker J, Shi SD, Gehring M, Sun S. Steady-state kinetic and inhibition studies of the mammalian target of rapamycin (mTOR) kinase domain and mTOR complexes. Biochemistry, 2010, 49: 8488-8498

2 Sabatini DM. mTOR and cancer: insights into a complex relationship. Nat Rev Cancer, 2006, 6: 729-734

3 Zoncu R, Efeyan A, Sabatini DM. mTOR: from growth signal integration to cancer, diabetes and ageing. Nat Rev Mol Cell Biol, 2011, 12: 21-35

4 Azim H, Azim HA Jr, Escudier B. Targeting mTOR in cancer: renal cell is just a beginning. Target Oncol, 2010, 5: 269-280

5 Inoki K, Li Y, Xu T, Guan KL. Rheb GTPase is a direct target of TSC2 GAP activity and regulates mTOR signaling. Gene Dev, 2003, 17: 1829-1834

6 Gwinn DM. Shackelford DB, Egan DF, Mihaylova MM, Mery A, Vasquez DS, Turk BE, Shaw RJ. AMPK phosphorylation of raptor mediates a metabolic checkpoint. Mol Cell, 2008, 30: 214-226

7 Morita M, Gravel SP, Chénard V, Sikström K, Zheng L, Alain T, Gandin V, Avizonis D, Arguello M, Zakaria C, McLaughlan S, Nouet Y, Pause A, Pollak M, Gottlieb E, Larsson O, St-Pierre J, Topisirovic I, Sonenberg N. mTORC1 controls mitochondrial activity and biogenesis through 4E-BP-dependent translational regulation. Cell Metab, 2013, 18: 698-711

8 Wang, X. Chrysovergis K, Kosak J, Kissling G, Streicker M, Moser G, Li R, Eling TE. hNAG-1 increases lifespan by regulating energy metabolism and insulin/IGF-1/mTOR signaling. Aging, 2014, 6: 690-704

9 Wu D, Yang M, Chen Y, Jia Y, Ma ZA, Boden G, Li L, Yang G. Hypothalamic nesfatin-1/NUCB2 knockdown augments hepatic gluconeogenesis that is correlated with inhibition of mTOR-STAT3 signaling pathway in rats. Diabetes, 2014, 63: 1234-1247

10 Saha AK, Vavvas D, Kurowski TG, Apazidis A, Witters LA, Shafrir E, Ruderman NB. Malonyl-CoA regulation in skeletal muscle: its link to cell citrate and the glucose-fatty acid cycle. AM J Physiol, 1997, 272: E641-E648

11 Yoon S, Lee MY, Park SW, Moon JS, Koh YK, Ahn YH, Park BW, Kim KS. Up-regulation of acetyl-CoA carboxylase alpha and fatty acid synthase by human epidermal growth factor receptor 2 at the translational level in breast cancer cells. J Biol Chem, 2007, 282: 26122-26131

12 Duvel K, Yecies JL, Menon S, Raman P, Lipovsky AI, Souza AL, Triantafellow E, Ma Q, Gorski R, Cleaver S, Vander Heiden MG, MacKeigan JP, Finan PM, Clish CB, Murphy LO, Manning BD. 
Activation of a metabolic gene regulatory network downstream of mTOR complex 1. Mol Cell, 2010, 39: 171-183

13 Peterson TR, Sengupta SS, Harris TE, Carmack AE, Kang SA, Balderas E, Guertin DA, Madden KL, Carpenter AE, Finck BN, Sabatini DM. mTOR complex 1 regulates lipin 1 localization to control the SREBP pathway. Cell, 2011, 146: 408-420

14 Kersten S. Mechanisms of nutritional and hormonal regulation of lipogenesis. EMBO J, 2001, 2: 282-286

15 Manning BD, Cantley LC. AKT/PKB signaling: navigating downstr- eam. Cell, 2007, 129: 1261-1274

16 Porstmann T, Santos CR, Griffiths B, Cully M, Wu M, Leevers S, Griffiths JR, Chung YL, Schulze A. SREBP activity is regulated by mTORC1 and contributes to Akt-dependent cell growth. Cell Metab, 2008, 8: 224-236

17 Wang H, Zhang Q, Wen Q, Zheng Y, Lazarovici P, Jiang H, Lin J, Zheng W. Proline-rich Akt substrate of 40kDa (PRAS40): a novel downstream target of PI3k/Akt signaling pathway. Cell Signal, 2012, 24: $17-24$

Open Access This article is distributed under the terms of the Creative Commons Attribution License which permits any use, distribution, and reproduction in any medium, provided the original author(s) and source are credited. 